\title{
Figurino docente
}

\author{
[ Teacher costume
}

\section{Alessandra Ancona de Faria ${ }^{\mathrm{I}}$}

\section{Ana Angélica Medeiros Albano}

RESUMO - Este artigo relata uma investigação-formação, na qual buscamos, pelo diálogo do teatro com a memória, perceber aspectos da docência muitas vezes ignorados nas reflexões sobre as relações docente-discente - em especial, um deles: o "figurino" dos professores. Investigamos elementos da cena teatral, relacionando-os à docência. Buscamos evidenciar posturas assumidas pelos professores e possibilitar a reflexão e o questionamento sobre elas. O ponto de partida foram as lembranças dos sujeitos pesquisados em relação às roupas de seus professores. A partir da síntese das roupas lembradas individualmente, criou-se um figurino coletivo em grupo, após a experiência com exercícios teatrais e a reflexão sobre qual imagem de professor gostariam de retratar. Este processo permitiu entrar em contato com aspectos significativos da docência, questioná-los e, em muitos casos, recriá-los. P PALAVRAS-CHAVE Formação de professores, Memória, Teatro, Figurino. - ABSTRACT This article brings a reflection on the "costumes" of teachers. We present a research in the field of teacher training, which is configured as a research-tra- ining, in which we seek, in the dialogue of the theater with memory, the perception of aspects of teaching that are often ignored in the reflections about the teaching-learning relationships. To this end, we set out to investigate elements of the theatrical scene in relation to teaching, starting from the hypothesis that these objects may show postures assumed by teachers and, thus, enable the reflection and questioning about the same. The starting point were teachers who have gone through life of the surveyed people and, in this exercise that we narrated, the focus were the memories of these teachers' clothes. This exercise with the memory enables to enter in contact with motivations that, possibly, guided some of your choices. The "costumes" created from those memories and experience with theatrical exercises led to the need for reflection on which image of teacher they would like to portray. This process enabled them to enter in contact with significant aspects of teaching, question them and, in many cases, recreate them. - KEYwords Teacher training, Memory, Theatre, Costume.

Recebido em I4 de maio de 2014

Aprovado em I6 de outubro de 2014

Faria, Alessandra Ancona; Albano, Ana Angélica Medeiros. Figurino docente. Revista do Instituto de Estudos Brasileiros, Brasil, n. 6I, p. 82-IO2, ago. 2015.

DoI: http://dx.doi.org/Io.II6o6/issn.23I6-90IX.voi6Ip82-I02

\footnotetext{
I Instituto Avisa Lá (São Paulo, Brasil).

2 Universidade Estadual de Campinas (Unicamp, São Paulo, Brasil).
} 
Com que roupa eu vou? Que roupa me traduz? Qual o figurino que expressa meus desejos, minhas opiniões, minhas crenças?

A composição do figurino no teatro há muito não se preocupa com a criação de uma roupa realista, que traduza apenas a época e o local onde o personagem vive, porque, em muitos espetáculos, esses dados dos personagens não estão explicitados ou não são valorizados.

O figurino teatral pode traduzir as emoções, os estados de espírito, os conflitos de cada personagem ou buscar a neutralidade que possibilite ao ator assumir diversos papéis. $O$ figurinista pode ainda criar apenas detalhes que simbolizem uma mudança de estado, um adereço que faça com que a plateia entenda que aquele ator agora mudou de personagem, que envelheceu, que se casou.

Roubine ${ }^{\mathrm{I}}$ afirma que

o figurino, por sua vez, deve ser considerado como uma variedade particular do objeto cênico. Pois se ele tem uma função específica, a de contribuir para a elaboração do personagem pelo ator, constitui também um conjunto de formas e cores que intervém no espaço do espetáculo, e devem portanto integrar-se nele.

$V$ Viana $^{2}$ e Muniz ${ }^{3}$ apresentam o percurso de diferentes encenadores, nos quais é possível observar a variedade de possibilidades e sentidos atribuídos ao figurino, assim como sua participação na construção do espetáculo. É possível perceber, nos estudos sobre figurino, a importância que este pode ter na criação de um personagem ou na elaboração da cena, conforme relatado por Viana em entrevistas a Gabriel Villela e Marie-Hélène Bouvet 4 .

E os professores, o que dizem com suas roupas? São roupas de uma pessoa e não figurino de um personagem, mas expressam, dizem algo para seus alunos, opinam sobre o que eles são e sobre suas escolhas na forma de ser docente.

A proposta de investigar elementos da cena teatral, relacionando-os à docência,

I ROUBINE, Jean J. A linguagem da encenação teatral. Rio de Janeiro, Jorge Zahar, I998, p. I46.

2 VIANA, Fausto R. P. O figurino teatral e as renovações do século XX. São Paulo: Estação das Letras, 20Io, v. I.

3 VIANA, Fausto R. P.; MUNIZ, Rosane (org.). Diário das escolas: cenografia. Rio de Janeiro: Funarte, 20II, v. I.

4 Além de diretor teatral, Villela tem atuação como cenógrafo e figurinista. Marie-Hélène Bouvet é figurinista do Cirque du Soleil. 
parte da hipótese de que esses elementos possam evidenciar posturas assumidas pelos professores, permitindo a reflexão e o questionamento sobre o quanto estas foram escolhas ou não.

A relação estabelecida com o figurino teatral deve-se ao fato desta pesquisa ter como um de seus pilares a improvisação teatral e a possibilidade de compreensão simbólica que as roupas docentes assumem, relacionando-se, assim, com o significado do figurino no teatro.

No estudo realizado com alunos de pedagogia de uma universidade pública e com professores de diferentes áreas de uma Fundação cuja escola desenvolve trabalhos assistenciais, investigamos a imagem docente, tendo como base as possibilidades criadas na improvisação teatral. Tal improvisação partiu dos elementos da cena e das memórias dos participantes sobre seus professores. Um dos aspectos explorados foi o figurino.

O trabalho com o figurino aconteceu na metade de um processo de doze encontros com o grupo de professores e quinze com o grupo de alunos. $O$ grupo de alunos era composto por 35 mulheres e um homem, que representavam $85 \%$ do curso de pedagogia, dos quais apenas II\% tinham experiência docente; $65 \%$ não tinham nenhuma formação em arte; 6I\% já haviam feito teatro; e 94\% já haviam lido peças teatrais.

No grupo de dezoito professores - quatro homens e catorze mulheres - , 4I\% eram graduados; $53 \%$, especialistas; e $6 \%$, mestres. Possuíam diferentes graduações: $35 \%$ haviam cursado pedagogia e os demais eram formados em moda, letras, sistema de informação, física, matemática, química, artes visuais, artes cênicas, ciências sociais e educação física. As disciplinas por eles lecionadas estavam diretamente relacionadas às suas formações específicas, o que possibilitou um grupo bastante diversificado. No momento da pesquisa, atuavam na Educação Infantil (I2\%), no Ensino Fundamental I (28\%), no Ensino Fundamental II (28\%), no Ensino Médio (26\%) e lecionavam em Cursinho (2\%), Curso Técnico (2\%) e Curso Superior (2\%). A maior parte (7I\%) lecionava somente na instituição na qual a pesquisa se realizou, e o restante lecionava também em outras instituições. $\mathrm{O}$ tempo de experiência docente desses professores era bastante variado: $23 \%$ haviam lecionado de um a dois anos; I $8 \%$, de três a cinco; $29 \%$, de seis a dez; $24 \%$, de onze a quinze; e $6 \%$, de dezesseis a vinte anos, $76 \%$ não possuíam nenhuma formação em arte, $65 \%$ nunca haviam feito teatro e $65 \%$ já haviam lido peças teatrais.

Esta pesquisa, que se configura como uma investigação-formação, teve como base a retomada de lembranças sobre os professores com os quais os participantes conviveram, recriadas na exploração teatral. As propostas desenvolvidas, tendo a história de vida dos estudantes/professores como possibilidade de reflexão e formação do professor, são inúmeras e caminham por diferentes percursos, mas em todas elas temos a referência das experiências vividas como fonte de reflexão.

A escolha da improvisação a partir das narrativas de história de vida foi motivada por permitir uma nova percepção sobre o fato narrado, estabelecendo diálogo com possibilidades de sua encenação.

Ao narrar sua própria história, a pessoa procura dar sentido às suas experiências e, nesse percurso, constrói outra representação de si: reinventa-se. Como sugere Larrosa, 
na epígrafe5, somos a narrativa aberta e contingente da história de nossas vidas, a história de quem somos em relação ao que nos acontece. ${ }^{6}$

A possibilidade de falar sobre suas experiências, sobre as lembranças de seus professores permite ao aluno/professor dar sentido ao vivido. Ao recordar-se de situações vividas como aluno, será possível perceber aspectos passados que constituíram a imagem docente.

Como nos fala Passegi, a percepção dessa história não é fixa, imutável, o que dá sentido ao processo de revisitá-la. Nesse olhar para os professores com os quais conviveram, os alunos/professores desse grupo puderam fazer escolhas, repensar práticas, reelaborar a maneira pela qual se viam como professores.

A reflexão sobre seu processo de formação não permite apenas situar-se numa história e numa continuidade temporal, ela conduz progressivamente o sujeito a questionar-se sobre sua visão do humano em sua dimensão terrestre (de que é feito o humano?) e em sua dimensão cósmica (o que é a humanidade?). Essa dupla dimensão tem o efeito de clarear a atitude do sujeito a respeito da aprendizagem e das atividades educativas.?

\section{O CORPO NO JOGO TEATRAL}

Devido à escolha de trabalharmos com a improvisação teatral, em todo o processo foi dada uma grande importância para a expressão do corpo: foram estabelecidas propostas que exploravam o contato com o próprio corpo e com o dos colegas, permitindo maior conhecimento e domínio das possibilidades expressivas corporais.

Inicialmente, foi proposto que os participantes deitassem no colchão e relaxassem, sentindo o corpo como se fosse uma massa, e fizessem movimentos de modelagem desta. Foi solicitado, em seguida, que voltassem a sentir seus corpos como compostos de ossos e músculos e pegassem um pedaço dessa massa em suas mãos para modelar um objeto ou uma forma. Na sequência, trabalharam em dupla, modelando uma única forma/objeto, sem combinar verbalmente nada do que seria feito.

A importância dada à percepção corporal é o que nos faz incluir neste texto o percurso pelo qual este processo se constituiu.

A linguagem teatral, assim como a dança, possibilita um conhecimento do próprio corpo e uma ampliação das possibilidades de vivência dele e com ele. Ao descobrir maneiras pelas quais podemos nos expressar corporalmente, descobrimos novas

5 "Lo que somos es la elaboración narrativa (particular, contingente, abierta, interminable) de la historia de nuestras vidas, de quién somos en relación a lo que nos pasa" (Jorge Larrosa).

6 PASSEGI, Maria C. A experiência em formação. Revista Educação - Dossiê Pesquisa (Auto) biográfica e Formação, v. 34, n. 2, p. I47, 2011.

7 JOSSO, Marie-Christine. Caminhar para si. Porto Alegre, EDIPUCRS, 20Io, p. I90. 
formas de nos movimentarmos, novas expressões e recursos que podemos utilizar na relação com outros corpos, nas relações sociais. ${ }^{8}$

Perceber que a maneira pela qual nos expressamos é uma dentre as muitas possibilidades com que nossos gestos podem ser ampliados; e que podemos ampliar a consciência sobre as formas de nos expressar corporalmente é a base para tomar consciência de como eu, professor, me expresso e de como posso ler, nos corpos dos meus alunos, aspectos que não são ditos por palavras.

A esse exercício corporal, continuamos o trabalho com o figurino em jogos teatrais que colocassem em questão a roupa e suas possibilidades de transformação: fizemos, por exemplo, o jogo das três mudanças ${ }^{9}$, no qual solicitaram-se inicialmente três alterações nas roupas, depois cinco e, então, sete ou mais, de maneira a criar personagens.

Nos dois grupos ficou evidente uma maior dificuldade para modificar-se quando estavam na dupla. Essa dificuldade foi relacionada ao fato de estarem sendo observados detalhadamente, e a maioria teve dificuldade em vislumbrar, inicialmente, mudanças possíveis em sua maneira de se vestir, de se apresentar.

Para uma das participantes, modificar a maneira de se vestir gerava um sentimento de invasão tão forte, que ela escolheu fazer modificações em sua maneira de se movimentar, nos seus gestos, para não alterar nenhuma roupa.

Foi interessante perceber que a maioria dos participantes encontrou muitas formas de transformar suas roupas, quando a solicitação foi de que criassem o figurino de um personagem, o que pode ser visto nas imagens apresentadas.

A criação do figurino do personagem implica um distanciamento da pessoa. Transformo as roupas no momento em que essa transformação e esse figurino não mais estão me apresentando pessoalmente, mas apresentam outro, o personagem que passo a representar. Esse distanciamento é o que permite que muitos atores possam experimentar tantos papéis, com valores e posicionamentos distantes dos escolhidos pessoalmente. É, também, na experimentação desse outro personagem que entendemos a importância do trabalho teatral como parte da formação humana, já que ele permite o exercício de alteridade pela experimentação de outra perspectiva.

A ideia de que somente com muitos recursos é possível criar um figurino e de que uma peça de roupa só pode ser utilizada de uma única maneira foi questionada, para permitir enfrentar o desafio desse jogo.

Um professor que colocou suas meias nas orelhas e seu cinto no nariz, criando um elefante como personagem, comentou ao final não se achar criativo e surpreendeu-se com a solução encontrada. Essa experiência evidenciou o quanto a possibilidade de ser criativo está relacionada a situações desafiadoras, à necessidade de criar e à possibilidade de reconhecer, em nosso dia a dia, situações nas quais nos permitimos ser criativos.

8 FARIA, Alessandra. A. Contar histórias com o jogo teatral. São Paulo, Perspectiva, 20II, p. I27.

9 Neste jogo proposto por Spolin, o jogador altera três elementos na maneira que ele está vestido e a sua dupla deve identificar quais foram. É um jogo que trabalha a percepção do outro e a flexibilidade para transformar-se (cf. SPOLIN, Viola. Jogos teatrais para a sala de aula: um manual para o professor. São Paulo, Perspectiva, 2008). 
No cotidiano docente, muitos desafios são apresentados, porém é pequena a percepção de que soluções novas possam resolver conflitos e impasses para a construção de conhecimento. Muitas vezes, o que observamos é a repetição de uma única maneira de lidar com as situações que se apresentam, pois o professor não percebe seu potencial de criar e, mesmo quando o percebe, não se autoriza a exercê-lo.

Nos dois grupos que participaram deste estudo, a criação ocorreu na transformação de suas roupas, e diversos tipos surgiram, como prostitutas ou freiras. Um dos alunos comentou que a criação do "personagem" pelo figurino revelou aspectos que ele não reconhecia como seus. Em seu figurino, o aluno amarrou um pano na cabeça e caminhava com uma postura de medo e de vergonha perante o grupo. Mostrava-se muito aberto e comunicativo, opinando sempre e procurando refletir sobre os aspectos debatidos, porém a situação de ser o único homem entre tantas mulheres provocava certo desconforto. Talvez o figurino escolhido por ele tenha também expressado aquilo que ele vivia com aquele grupo, mesmo que não caracterizasse sua personalidade. A essa experiência se aplica a afirmação de Fischer ${ }^{\mathrm{IO}}$ :

a função permanente da arte é recriar para a experiência de cada indivíduo a plenitude daquilo que ele não é, isto é, a experiência de toda a humanidade. A magia da arte está em que nesse processo de recriação, mostra a realidade como passível de ser transformada, dominada e tornada brinquedo.

O exercício de uma linguagem artística parece ter possibilitado olhar, experienciar e recriar a realidade a partir daquilo que não se é, mas que existe como possibilidade ou como o avesso que revela a falta ou o desconforto. Neste exercício com o figurino, ao compor personagens, foi possível essa experimentação. Os grupos de alunos e de professores puderam, através dos papéis exercidos, brincar com a realidade e perceber características e possibilidades não notadas até então.

Tendo esse primeiro momento como disparador para a percepção das roupas e das possibilidades de sua transformação, solicitamos que cada um se lembrasse de um professor e da forma como ele, ou ela, se vestia e desenhasse esse professor.

\section{FIGURINOS INDIVIDUAIS}

A proposta de trabalhar com a memória dos professores permitiu que olhassem para suas lembranças com a distância dos anos e entrassem em contato com motivações que, possivelmente, orientaram algumas de suas escolhas.

O sujeito que constrói sua narrativa e que reflete sobre sua dinâmica é o mesmo que vive sua vida e se orienta em cada etapa. Dizer isso equivale a colocar o sujeito no centro do processo de formação. É fazer dele o escultor de sua existência, mesmo se o material sobre o qual trabalha impõe exigências conhecidas ou inesperadas. ${ }^{\text {II }}$

Io FISCHER, Ernst. A necessidade da arte. Rio de Janeiro, Zahar, I967, p. 252.

II JOSSO, Marie-Christine, op. cit., p. I95. 
Recordar seus professores possibilitou ao grupo de alunos e professores a percepção das influências vividas no cotidiano escolar. Pensar em suas roupas e desenhá-las, escolher dentre os vários professores com os quais cada um conviveu qual havia sido marcante, qual trajava roupas que ficaram na memória foi uma maneira de refletir sobre a importância da identidade expressa na escolha de como se vestir.

Um terno de pedra, preto, como uma armadura. Quantos botões desnecessários neste terno (na disciplina sobre Marx!). E a gravata, o nó sufocante na garganta, dela, apenas o vermelho não se encontrava em contradição. Em um curso sobre Marx (!) a veste burguesa mais descarada. O próprio autor - li depois - comentava sobre o terno burguês. Contudo, naquele conjunto, onde a veste era mais que o professor, havia algo não postiço: uma bengala. $\mathrm{O}$ terceiro membro do enigma da esfinge elidia um pouco a atenção daquele terno de pedra. Ela segura as pernas cambaleantes do tempo transcorrido no corpo do professor Rubens e dizia, diferente do enigma egípcio (sic) que nos petrifica, que o enigma do tempo nos faz areia. ${ }^{\mathrm{T} 2}$

Os quadros I e 2 apresentam os figurinos desenhados individualmente: no quadro I estão as escolhas feitas pelos alunos de graduação e, no quadro 2, as escolhas pelos professores. Evidentemente, a apresentação em forma de um quadro, que sintetiza os desenhos e os textos apresentados pelos participantes, não permite uma aproximação completa com os elementos expressos, porém a apresentação destes dados permitirá um melhor entendimento dos figurinos coletivos, assim como dos aspectos abordados no texto. Mantivemos, sempre que possível, o texto apresentado pelos participantes.

Professor de que época

\begin{tabular}{|l|l|l|}
\hline $\begin{array}{l}\text { Nenhum professor espe- } \\
\text { cífico }\end{array}$ & Não foi explicitado. & $\begin{array}{l}\text { Uma blusa colorida, com dese- } \\
\text { nho de pássaro e flores, man- } \\
\text { chada. }\end{array}$ \\
\hline $\begin{array}{l}\text { Nenhum professor espe- } \\
\text { cífico }\end{array}$ & $\begin{array}{l}\text { O uso de uma roupa ou acessório diferente } \\
\text { do habitual, como um vestido, ser motivo } \\
\text { de comentários. }\end{array}$ & $\begin{array}{l}\text { Vestido florido, batom, bolsa pe- } \\
\text { quena cruzada, faixa na cintura. }\end{array}$ \\
\hline Matemática/ artesanato & $\begin{array}{l}\text { extrovertida e se dava bem com todos na } \\
\text { escola (característica com a qual a aluna } \\
\text { se identifica). }\end{array}$ & $\begin{array}{l}\text { Cores alegres, muitos colares, } \\
\text { saias estampadas e uma rastei- } \\
\text { rinha bem simples. }\end{array}$ \\
\hline $3^{\text {a série }}$ & $\begin{array}{l}\text { Parecia uma boneca, tinha um aspecto } \\
\text { infantil. }\end{array}$ & $\begin{array}{l}\text { Saia jeans com sapatos de boneca } \\
\text { de todas as cores. }\end{array}$ \\
\hline
\end{tabular}

Trecho de um dos textos redigidos por um aluno da graduação. 


\begin{tabular}{|c|c|c|}
\hline $3^{\mathrm{a}}$ série & $\begin{array}{l}\text { Por ser o professor de quem ela mais lem- } \\
\text { bra. }\end{array}$ & Tênis, bermuda e camiseta. \\
\hline $3^{\mathrm{a}}$ ou $4^{\mathrm{a}}$ série & $\begin{array}{l}\text { Curiosidade em saber o que estava por bai- } \\
\text { xo da roupa e qual a cor do cabelo. }\end{array}$ & $\begin{array}{l}\text { Saia preta e blusa social bege, sa- } \\
\text { patinho preto e um véu que não } \\
\text { permitia ver nem um pedacinho } \\
\text { do cabelo. }\end{array}$ \\
\hline $5^{\mathrm{a}}$ série - matemática & $\begin{array}{l}\text { Contradição entre a professora com a blusa } \\
\text { de mangá e a que a substituiu, que usava } \\
\text { avental por acreditar que os professores } \\
\text { não deveriam usar roupas inadequadas. }\end{array}$ & $\begin{array}{l}\text { Blusa sintética com desenho de } \\
\text { mangá, que aparecia a barriga. }\end{array}$ \\
\hline $5^{\mathrm{a}}$ série & $\begin{array}{l}\text { Os meninos da sala reparavam no formato } \\
\text { da calcinha e no sutiã, que era mais escuro } \\
\text { que a blusa. }\end{array}$ & $\begin{array}{l}\text { Calça agarrada preta, camisa } \\
\text { branca ou rosa claro, cabelo cur- } \\
\text { to, tênis All Star preto. }\end{array}$ \\
\hline $6^{a}$ série - geografia & $\begin{array}{l}\text { Gosto eclético, às vezes combinava tanto as } \\
\text { roupas que ficava brega. }\end{array}$ & $\begin{array}{l}\text { Roupas que marcavam muito, } \\
\text { floridas, coloridas e alegres. (No } \\
\text { desenho a professora é bem bun- } \\
\text { duda). }\end{array}$ \\
\hline $\begin{array}{l}6^{\mathrm{a}} \text { série professor de gra- } \\
\text { mática }\end{array}$ & Professor usou no primeiro dia de aula. & $\begin{array}{l}\text { Camiseta com uma imagem de } \\
\text { alguém com algo na cabeça, que } \\
\text { acena. }\end{array}$ \\
\hline $7^{\mathrm{a}}$ série - ensino religioso & Não foi explicitado. & $\begin{array}{l}\text { Uma saia amarela abaixo do joe- } \\
\text { lho, sapato azul de pouco salto, } \\
\text { blusa rosa com uma faixa amare- } \\
\text { la na cintura, sem decote e uma } \\
\text { bolsa nas mãos. }\end{array}$ \\
\hline $7^{\mathrm{a}}$ série - geografia & $\begin{array}{l}\text { Combinava suas roupas pela cor, incluindo } \\
\text { acessórios e meias. }\end{array}$ & $\begin{array}{l}\text { Calça rosa, blusa rosa acinzenta- } \\
\text { da, colar cinza, sapato cinza. }\end{array}$ \\
\hline Ensino Médio & $\begin{array}{l}\text { Roupas ousadas, apesar da idade avançada } \\
\text { (45) e tinha um discurso contra o consu- } \\
\text { mismo, dizendo que comprava suas rou- } \\
\text { pas no supermercado, mas usava roupas } \\
\text { de marca. }\end{array}$ & $\begin{array}{l}\text { Vestido decotado e curto, preto } \\
\text { e vermelho, aparecendo as alças } \\
\text { do sutiã vermelho. A barra do } \\
\text { vestido é em pontas. }\end{array}$ \\
\hline
\end{tabular}




\begin{tabular}{|c|c|c|}
\hline $\begin{array}{l}2^{\circ} \text { ano do Ensino Médio - } \\
\text { matemática }\end{array}$ & $\begin{array}{l}\text { Vestia-se muito bem, bonita e elegante. } \\
\text { Uma professora que a fez entender mate- } \\
\text { mática; boazinha, mas exigente, que con- } \\
\text { seguia prender a atenção de todos. }\end{array}$ & $\begin{array}{l}\text { Um vestido longo, azul-marinho } \\
\text { com flores brancas, combinando } \\
\text { com as sandálias de plataforma } \\
\text { azul e branca; parecia ser de } \\
\text { malha, ficava caído e rodado na } \\
\text { barra. O jaleco por cima, usado } \\
\text { às vezes, atrapalhava. }\end{array}$ \\
\hline Ensino Médio - biologia & $\begin{array}{l}\text { Uma das professoras mais bonitas da esco- } \\
\text { la, mas que usava uma cinta compressora } \\
\text { que era possível ver quando a blusa subia. }\end{array}$ & $\begin{array}{l}\text { Calça jeans ou social, camisetas } \\
\text { ou blusinhas, cabelos pretos sol- } \\
\text { tos, bijuterias e joias e maquia- } \\
\text { gem nos olhos. }\end{array}$ \\
\hline $\begin{array}{l}I^{\circ} \text { ano do Ensino Médio - } \\
\text { inglês }\end{array}$ & Sempre bem arrumada. & $\begin{array}{l}\text { Salto, anéis, pulseiras, colares e } \\
\text { brincos (não tudo de uma vez). }\end{array}$ \\
\hline $\begin{array}{l}\text { Professora de biologia do } \\
\text { Ensino Médio e diretora }\end{array}$ & $\begin{array}{l}\text { Vontade de saber o que havia debaixo da } \\
\text { roupa e qual a cor do cabelo. Motivo de ri- } \\
\text { sada e piadas dos alunos. }\end{array}$ & Hábito de freira. \\
\hline Ensino Médio - química & Coleção de casaquinhos. & $\begin{array}{l}\text { Casaquinhos todos iguais de vá- } \\
\text { rias cores, gola careca, com bo- } \\
\text { tões e barrado. }\end{array}$ \\
\hline Ensino Médio - geografia & $\begin{array}{l}\text { Sempre usava a mesma roupa. Diziam que } \\
\text { ele era comunista. }\end{array}$ & $\begin{array}{l}\text { Camisa cinza, calça jeans e sapa- } \\
\text { to preto. }\end{array}$ \\
\hline I5 anos & Não foi explicitado. & $\begin{array}{l}\text { Vestido preto tomara-que-caia, } \\
\text { com o nome dos alunos no bar- } \\
\text { rado branco, sapato de salto. }\end{array}$ \\
\hline $\begin{array}{l}\text { Escolheu quatro professo- } \\
\text { res:de literatura, do Ensi- } \\
\text { no Médio e da faculdade. }\end{array}$ & Não foi explicitado. & $\begin{array}{l}\text { Dois deles usavam calça jeans } \\
\text { rasgada, tênis All Star e senta- } \\
\text { vam sobre a mesa com pernas } \\
\text { cruzadas. Os outros dois usavam } \\
\text { calça social, sendo que um deles } \\
\text { era "afrancesado" e o outro tinha } \\
\text { amendoim no bolso da camisa. }\end{array}$ \\
\hline Faculdade & $\begin{array}{l}\text { Uma velhinha fofa, que lembra uma cari- } \\
\text { catura. }\end{array}$ & $\begin{array}{l}\text { Faixa no cabelo, com os óculos da } \\
\text { mesma cor, três relógios, meias } \\
\text { de cores berrantes, saia longa, } \\
\text { blusa de bolinhas e blusa de frio } \\
\text { amarrada na cintura. }\end{array}$ \\
\hline
\end{tabular}




\begin{tabular}{|l|l|l|}
\hline Faculdade & $\begin{array}{l}\text { Roupa (terno) que contraria o discurso } \\
\text { marxista. }\end{array}$ & $\begin{array}{l}\text { Terno com gravata vermelha e } \\
\text { bengala. }\end{array}$ \\
\hline Faculdade - sociologia & Lembra a avó. & Delicadas e estampadinhas. \\
\hline Faculdade & Impecavelmente bem vestida & Vestido e salto alto. \\
\hline Faculdade & $\begin{array}{l}\text { Uma pessoa segura, que está pouco se fu- } \\
\text { dendo para o que os outros pensam. }\end{array}$ & $\begin{array}{l}\text { Não combinar as cores das rou- } \\
\text { pas }\end{array}$ \\
\hline Faculdade & $\begin{array}{l}\text { Ter achado um charme a dama de verme- } \\
\text { lho. }\end{array}$ & $\begin{array}{l}\text { Vestido vermelho com flores ala- } \\
\text { ranjadas e meias vermelhas. }\end{array}$ \\
\hline Faculdade - antropologia & $\begin{array}{l}\text { Usava roupas muito estilosas, desejadas. } \\
\text { Identificava-se com ela. }\end{array}$ & $\begin{array}{l}\text { Cabelo loiro e cacheado, às vezes } \\
\text { preso de forma diferente e esti- } \\
\text { losa. }\end{array}$ \\
\hline Faculdade & $\begin{array}{l}\text { tres; quer ser como ela, inspira-se nela. } \\
\text { daca }\end{array}$ & $\begin{array}{l}\text { Vestido rosa com desenhos abs- } \\
\text { tratos em azul e rosa; sapato de } \\
\text { salto. }\end{array}$ \\
\hline
\end{tabular}

Quadro I. Figurinos individuais Unicamp

Quanto às escolhas de professores, observamos que 30\% são de professores da faculdade e 30\% do Ensino Médio, isto é, os alunos escolheram, em geral, professores com os quais tiveram contato mais recentemente. Um dos fatores que pode ter pesado nessa escolha é ser a lembrança mais clara. Com relação aos motivos que levaram à escolha de um determinado professor, embora qualquer agrupamento ignore detalhes individuais, podemos notar que $45 \%$ escolheram professores que se preocupavam com a aparência, que se mostravam elegantes ou bonitos; $20 \%$ escolheram professores que utilizavam roupas que, de alguma forma, despertavam a curiosidade pela sexualidade; I5\% escolheram roupas que confirmavam ou contradiziam o discurso apresentado pelo professor; Io\% escolheram um professor que despertou a afetividade (relação com a avó); $5 \%$ escolheram por ser uma roupa diferente da dos demais professores e $5 \%$ foram movidos pela identificação com o professor. De um total de 29 participantes, não foi possível classificar oito: quatro por não terem apresentado a razão da escolha e quatro por não terem se encaixado em nenhuma destas categorias. 


\begin{tabular}{|c|c|c|}
\hline Não informado. & Não foi explicitado. & $\begin{array}{l}\text { Um homem com cabelo espeta- } \\
\text { do, cigarro na boca, desenhado } \\
\text { em duas situações: uma delas ao } \\
\text { lado de uma bicicleta, e a outra } \\
\text { com uma maleta e um bastão de } \\
\text { onde parece sair fogo, de seus } \\
\text { bolsos também saem coisas. }\end{array}$ \\
\hline Não informado. & $\begin{array}{l}\text { A falta de cor e a repetição de rou- } \\
\text { pas. }\end{array}$ & $\begin{array}{l}\text { A falta de cor e a repetição de } \\
\text { roupas. }\end{array}$ \\
\hline Não informado. & $\begin{array}{l}\text { Usar avental com a marca da em- } \\
\text { presa onde trabalha bordada no } \\
\text { bolso. }\end{array}$ & $\begin{array}{l}\text { Professor careca, com um aven- } \\
\text { tal grande com a marca Bosch } \\
\text { bordada no bolso; óculos qua- } \\
\text { drado. }\end{array}$ \\
\hline Não informado. & $\begin{array}{l}\text { Livre de preocupação com o pa- } \\
\text { drão; às vezes passa o ar de rela- } \\
\text { xado. }\end{array}$ & Calça com a barra desfeita. \\
\hline Não informado. & Uniformes padronizados. & $\begin{array}{l}\text { Camisa vermelha com um bolso } \\
\text { pequeno do lado esquerdo. }\end{array}$ \\
\hline$I^{a}$ série & $\begin{array}{l}\text { A professora estar sempre enfei- } \\
\text { tada. }\end{array}$ & $\begin{array}{l}\text { Vestido, meia-calça, sapato de } \\
\text { salto, brincos, colar e pulseira. }\end{array}$ \\
\hline Seis anos & $\begin{array}{l}\text { O fato de a professora estar sempre } \\
\text { vestida da mesma forma. }\end{array}$ & $\begin{array}{l}\text { Calça e camisa jeans, lenço ver- } \\
\text { melho na cintura, tiara mostar- } \\
\text { da, cabelo solto e sapato de boli- } \\
\text { nha na sola. }\end{array}$ \\
\hline Oito anos & Saia e blusa bem alinhadas. & $\begin{array}{l}\text { Saia vermelha de pregas, blusa } \\
\text { com botões e detalhes no punho, } \\
\text { cinto. }\end{array}$ \\
\hline Dez anos & $\begin{array}{l}\text { A professora usar sempre um jale- } \\
\text { co sujo de giz atrás e, às vezes, com } \\
\text { riscos na frente. }\end{array}$ & $\begin{array}{l}\text { Jaleco amarelo com botões azuis, } \\
\text { sujo de giz. }\end{array}$ \\
\hline $\begin{array}{l}7^{\mathrm{a}} \text { série - Expressão cor- } \\
\text { poral }\end{array}$ & $\begin{array}{l}\text { Roupa larga, confortável, de al- } \\
\text { godão, que se movimentava junto } \\
\text { com o professor. }\end{array}$ & $\begin{array}{l}\text { Calça solta, sapato tipo chinelo } \\
\text { de dedo, blusa solta, regata. }\end{array}$ \\
\hline $2^{\circ}$ e $3^{\circ}$ colegial & $\begin{array}{l}\text { Professor que trocava de blusa no } \\
\text { verão, pois suava muito. }\end{array}$ & $\begin{array}{l}\text { Calça jeans e camisa laranja, } \\
\text { que era trocada por uma rosa no } \\
\text { verão. }\end{array}$ \\
\hline
\end{tabular}




\begin{tabular}{|c|c|c|}
\hline Colegial & $\begin{array}{l}\text { Ter ouvido de um colega que ela } \\
\text { se vestia da mesma maneira que a } \\
\text { professora, o que a deixou arrasa- } \\
\text { da, pois em sua visão a professora } \\
\text { usava roupas estranhas, antigas e } \\
\text { fora da moda. Hoje, ela concorda } \\
\text { com o menino. }\end{array}$ & $\begin{array}{l}\text { Calça azul, grudada no corpo, } \\
\text { sapato rosa, blusa rosa com flo- } \\
\text { res de várias cores e botões, bem } \\
\text { folgada, tipo bata. }\end{array}$ \\
\hline $\begin{array}{l}\text { Professor de handebol da } \\
\text { faculdade }\end{array}$ & Só usava agasalho Adidas. & $\begin{array}{l}\text { Agasalho azul, com a marca Adi- } \\
\text { das; usa óculos. }\end{array}$ \\
\hline Faculdade & $\begin{array}{l}\text { Roupas diferentes, difíceis de en- } \\
\text { contrar, pareciam ser compradas } \\
\text { em um brechó. }\end{array}$ & $\begin{array}{l}\text { Calça pantalona verde, blusa } \\
\text { vermelha, cinto vermelho, sapa- } \\
\text { to tipo boneca, bolsa roxa de te- } \\
\text { cido, combinando com o sapato, } \\
\text { anel grande. }\end{array}$ \\
\hline $\begin{array}{l}\text { Um colega, há quatro } \\
\text { anos. }\end{array}$ & $\begin{array}{l}\text { Jeito excessivamente tranquilo de } \\
\text { se vestir, passando a sensação de } \\
\text { estar tudo bem sempre. }\end{array}$ & $\begin{array}{l}\text { Calça larga e blusa tipo bata, bem } \\
\text { larga. }\end{array}$ \\
\hline
\end{tabular}

Quadro 2 . Figurinos individuais FAACG

Das escolhas feitas pelos professores, observamos que 33\% não definiram de que momento era o professor escolhido e 27\% escolheram professores do Ensino Fundamental I. Diferentemente dos alunos que ainda estão na graduação, a lembrança dos professores não se dá, na maior parte dos casos, pela proximidade temporal, pois, para vários deles, já se passaram muitos anos de distância da faculdade, quando tiveram seus últimos professores. Com relação aos motivos que levaram à escolha de um professor, $39 \%$ escolheram roupas que aparentavam conforto e rompiam com o padrão estabelecido, $38 \%$ escolheram uma roupa que se assemelhava a um uniforme, seja o uso de um jaleco ou a repetição da roupa e $23 \%$ escolheram pela beleza e elegância. De um total de quinze participantes, dois deles não puderam ser classificados: um por não ter apresentado a razão da escolha e outro por não ter se encaixado em nenhuma destas categorias.

Podemos observar uma predominância de professoras nas lembranças individuais, principalmente dos alunos da Unicamp. Nos figurinos coletivos as representações femininas são ainda mais presentes, como pode ser visto a seguir.

\section{FIGURINOS COLETIVOS}

Feitos os desenhos individuais, foram formados grupos para a criação de um figurino que expressasse alguma característica relevante da docência. Esclarecemos que os 
figurinos desenhados tiveram como proposta a escolha de somente um aspecto da docência, o que não permitiu aos grupos a apresentação da possível diversidade na concepção de seus integrantes, sobre ser professor.

As dificuldades com o desenho também é um dado que interfere nas soluções visuais encontradas. As análises apresentadas, embora busquem trazer as motivações das participantes, é das pesquisadoras, que fazem uso de suas vivências e seus valores na interpretação das imagens apresentadas.

Os figurinos desenhados, expostos nas imagens I e 2, apresentam a ideia de professor expressa por esses dois grupos:
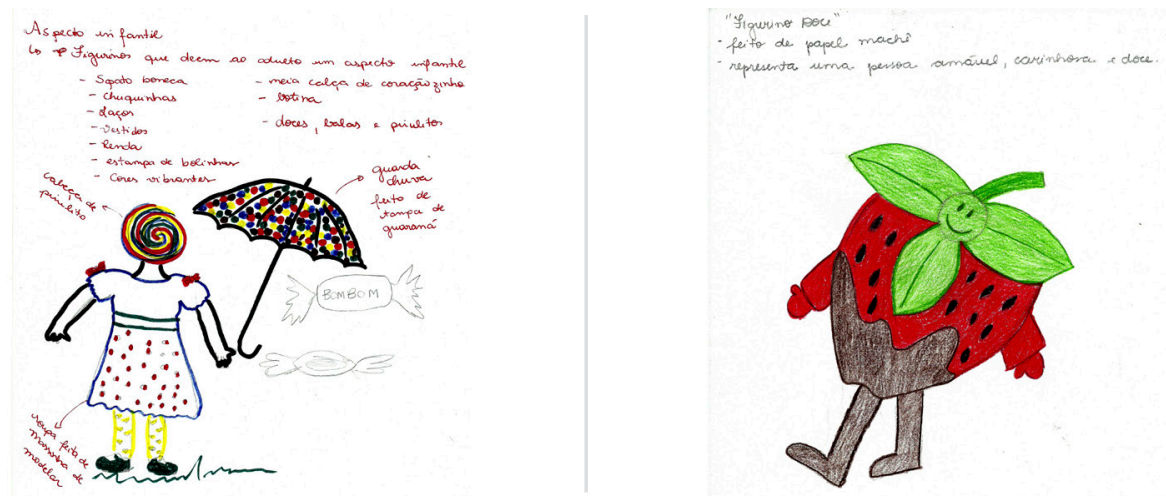

Imagens I (esquerda) e 2 (direita)

Nas imagens I e 2 existe a intenção de representar a infância, a docilidade, o carinho. Na imagem I as alunas criaram um figurino infantil. Escreveram: "Aspecto Infantil: Figurinos que deem ao adulto um aspecto infantil. Sapato boneca, chuquinhas, laços, vestidos, rendas, estampas de bolinhas, cores vibrantes, meia-calça de coraçãozinho, doces, balas, pirulitos, cabeça de pirulito, guarda-chuva feito de tampa de guaraná, roupa feita de massinha de modelar". É um figurino que traz elementos da infância, mas vale observar que a ideia de infância é semelhante à apresentada nos bufês infantis, onde a criança só gosta de muitas cores vibrantes e de doces, e a professora é infantilizada. A imagem 2 apresenta o figurino como "doce, feito de papel machê, representa uma pessoa amável, carinhosa e doce". Este figurino remete ainda mais claramente aos personagens infantis apresentados pelos programas para crianças. Embora o desenho não seja o mesmo, existe uma boneca chamada Moranguinho, que tem cara e corpo de uma menina, mas se veste com estampas de morango e está sempre com um morango ao lado.

Nessas primeiras imagens, podemos perceber a importância dada ao amor, ao carinho, à docilidade, à bondade e à meiguice. Chama a atenção a associação dessas características com a infantilização da imagem da professora. A ideia de criança também é fortemente influenciada pelos produtos comercializados para elas. É como se, para que a relação entre professora e aluno seja pautada pelos sentimentos amorosos, tanto a professora como as crianças necessitassem assumir esse mundo da infância abobalhada, vendida constantemente em muitos produtos, programas infantis e espaços destinados às crianças. 
Rios $^{\mathrm{I3}}$ discute essa ideia de felicidade, ao relacionar o conceito de felicidade com o de cidadania, propondo o questionamento dessa busca da alegria constante.

É preciso deixar de lado a ideia "hollywoodiana" de felicidade, identificada com uma vida "cor-de-rosa", sem conflitos e contradições. Se afirmarmos que a felicidade é outro nome para o bem comum e que o bem comum é o bem coletivo, bem público, queremos dizer que ela se identifica com a possibilidade de participar criativamente da sociedade, dizer sua palavra, ser ouvido e reconhecido em sua identidade, ser considerado e saber considerar no coletivo.

As imagens apresentadas nos figurinos trazem esse mundo "cor-de-rosa", com uma perspectiva de felicidade permanente, na qual não se reconhecem identidades, não se escutam as palavras particulares de cada professor ou aluno.

A música "Ciranda da Bailarina", de Chico Buarque, mostra a bailarina também como uma pessoa que não tem nenhum problema, nenhuma sujeira, nada de feio. Ela, bailarina, está, assim como estas professoras, habitando esse espaço de felicidade incondicional, sem conflitos, sem particularidades, onde só cabem a beleza e a perfeição. Vale pensar qual perspectiva de amor e de carinho está proposta nessa relação entre professoras e alunos.

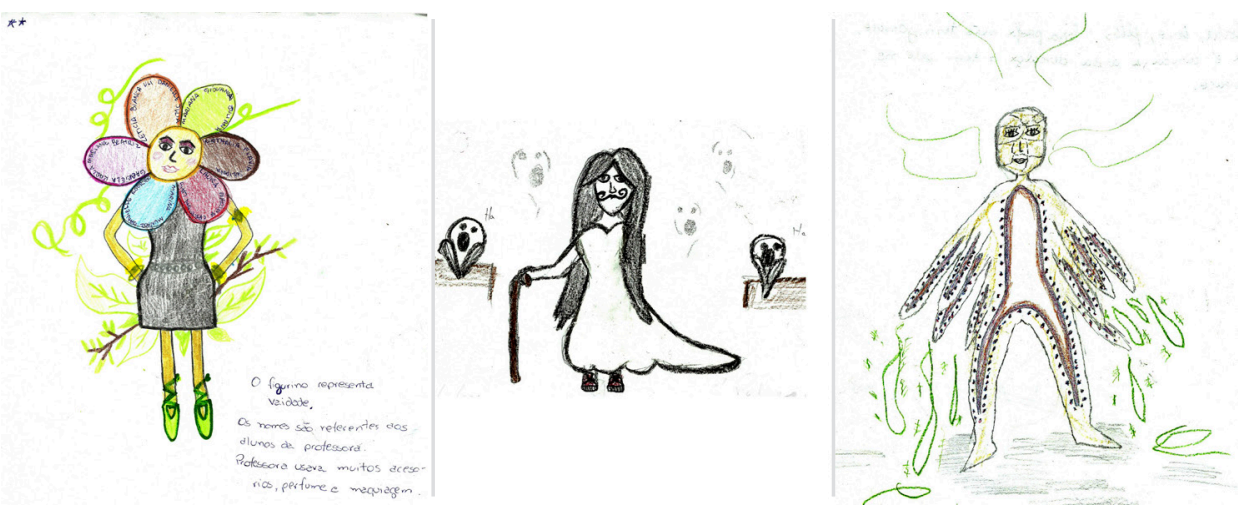

Imagens 3 (esquerda), 4 (centro) e 5 (direita)

A imagem 3 apresenta uma pessoa com uma flor no lugar do rosto, onde cada pétala é de uma cor e tem, escritos, os nomes dos alunos. No corpo usa um vestido cinza curto, e sapatilhas verdes de bailarina. Nas costas tem folhas e troncos; utiliza diversas pulseiras. Segundo as participantes, "o figurino representa vaidade e foi baseado em uma professora que usava muitos acessórios, perfume e maquiagem". Apesar dessa explicação sobre a motivação do desenho, é interessante observar a escolha de um figurino no qual a professora tem troncos e folhas presas ao seu corpo e carrega em seu rosto os nomes de todos seus alunos, que a fazem ficar com uma cara redonda, desprovida de traços humanos, pois seus olhos, nariz e boca são

I3 RIOS, Terezinha. A. Compreender e ensinar: por uma docência da melhor qualidade. São Paulo, Cortez, 200I, p. I20, grifos da autora. 
estilizados. O sapato da professora tampouco é o de uma mulher vaidosa, mas, sim, de uma bailarina, em posição de ponta, o que sugere, ao mesmo tempo, equilíbrio, rigidez e, para quem já ficou nas pontas de uma sapatilha, sofrimento.

A imagem 4 apresenta o figurino de uma noiva com uma bengala, tênis All Star vermelho e bigode. O grupo de alunos informou buscar demonstrar a contradição permanente de muitos professores. No desenho é possível observar, ao redor da professora, caras que fazem lembrar a imagem de "O Grito" de Edvard Munch, pois, além da surpresa, essas caras expressam sofrimento. É interessante observar a escolha do tênis All Star vermelho, "simbolizando a influência das discussões pretensamente revolucionárias". Mesmo com todo o estranhamento causado pela figura, ela sequer se aprofunda no que faz, já que suas discussões se pretendem revolucionárias, mas não são. Talvez para compensar a escolha do tênis ou a pretensão de ser revolucionária sem conseguir, a bengala é apontada como elemento indispensável para evidenciar "o quanto não podemos ser totalmente supérfluos". Esse desenho foi feito pelo grupo no qual estava o único homem da turma e é o único que traz aspectos do masculino em sua composição.

A imagem 5 mostra um figurino com uma cara em pedaços, vários braços e pernas. Não tem sexo. Segundo as autoras, "caracteriza aquilo que está saindo do professor, como baba, bafo, pelos". Se, nas imagens 3 e 4, o figurino que caracteriza o professor apresenta deformações, causando estranhamento, a imagem 5 se aprofunda nessa proposta e causa nojo. Uma cara feita por pedaços, desfigurada, que remete à falta de unidade, de coerência e onde sobra sofrimento, suportada por um corpo que baba, que deixa para seus alunos os excrementos, além de ter muitos braços, o que sugere a impossibilidade de que esses alunos escapem.

Os figurinos 3, 4 e 5 apresentam aspectos do professor que estão longe dos dois anteriores. Nestes, o sofrimento é trazido de forma contundente, não se vê nos professores a possibilidade da relação amorosa, nenhum dos três inspira aproximação ou carinho. Saímos de um oposto ao outro.

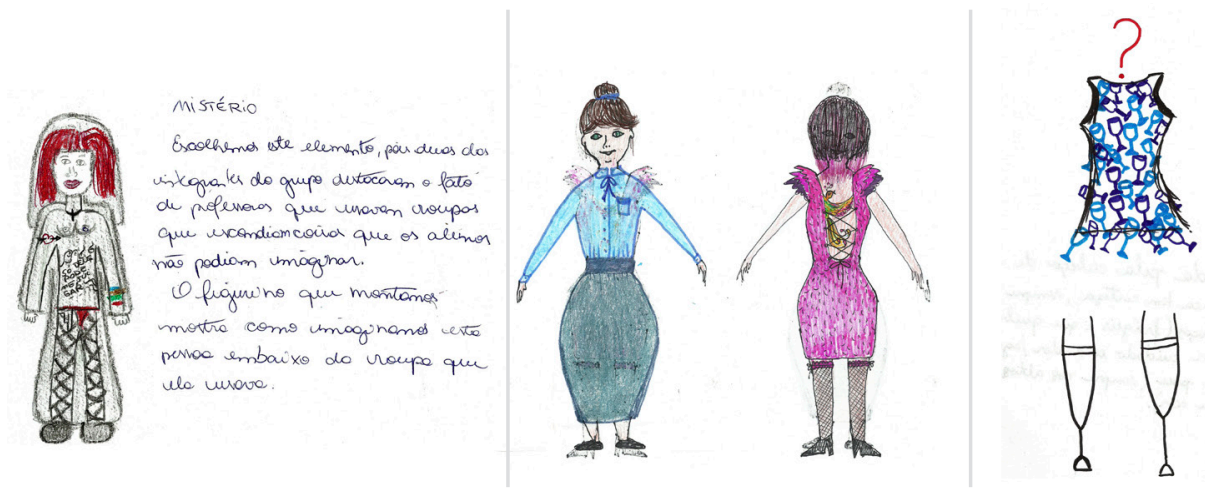

Imagens 6 (esquerda), 7 (centro) e 8 (direita) 
Na imagem 6, o figurino partiu da situação de imaginar o que as freiras usavam por baixo de seus hábitos. No relato sobre o figurino, as alunas contaram as várias suposições que haviam levantado. $\mathrm{O}$ figurino expressa as muitas possibilidades de leitura, pelos alunos, da forma como os professores se vestem, o que revelam de si e o que escondem. Neste caso, o fato de as professoras serem freiras e usarem hábito gerou no grupo de alunos diferentes fantasias, em sua maioria sexuais, o que pode ser visto na opção por desenhar uma meia arrastão, uma calcinha vermelha, cabelos igualmente vermelhos, tatuagem, seios e a frase: “Só Deus pode me ajudar". Vale observar que embora os elementos do figurino remetam a uma mulher, seu corpo é de uma adolescente, ainda sem curvas.

A imagem 7, composta por dois desenhos, sendo um a frente e o outro, o verso ${ }^{\mathrm{It}}$, não é de uma freira, mas apresenta, também, a mesma ideia de que as professoras escondem sua essência em roupas que não as representam. $O$ figurino mostra a roupa de uma senhora inteiramente coberta por saia longa e blusa fechada nos punhos e no decote. Nesta imagem não há qualquer possibilidade de sensualidade, até os cabelos são domados em um coque. O verso desta imagem é de um figurino de um vestido curto, com meia arrastão, tatuagem, decote, salto e cabelo curto, não mais no coque. A frente não é de uma freira, mas quase.

As duas imagens, 6 e 7, apresentam a ideia de que as professoras aparentam aquilo que não são, que mostram em suas roupas profissionais uma ausência de sexualidade, mas essa mesma sexualidade é bastante exagerada em sua vida privada.

A última imagem - de número 8 - criada pelos alunos é de um vestido feito com taças de cristal, que tem um ponto de interrogação no lugar da cabeça e pernas de pau. Ao apresentarem esse figurino, as alunas revelaram ser a representação de uma pessoa insegura, que tem sempre dúvida. A fragilidade expressa nesse figurino demonstra o professor como alguém que não tem qualquer domínio sobre suas ações e tem dúvidas sobre suas ideias.

A proposta de criação de um figurino que expressasse a imagem de professor poderia implicar a escolha de um aspecto a ser retratado, pois expressar muitos aspectos ofereceria o risco de que nenhum ficasse claro. Evidentemente, ao fazer uma escolha, as demais características tiveram que ser ignoradas, porém chama a atenção o fato de que as características mais positivas escolhidas são retratadas de maneira estereotipada, como nos figurinos I e 2. Já os outros figurinos apresentam uma imagem do professor como alguém vaidoso e pesado, contraditório, nojento, dissimulado e frágil.

Os corpos que, supostamente, carregam estes figurinos apresentam características interessantes e diversas. Na imagem I vemos um corpo infantilizado, assim como seu figurino, a imagem 2 não é de um corpo humano, a 3 e a 4 são femininos, já que possuem busto demarcado e quadril definido, embora as pernas da quatro sejam de uma criança. A imagem 6 se assemelha a uma adolescente, é uma mulher,

I4 No desenho, foi apresentada a imagem da professora de coque e, na sequência, o verso, no qual ela está totalmente transformada. Com o movimento de girar o papel, foi possível ver essa ideia de ser uma mesma pessoa em dois figurinos. $\mathrm{O}$ formato do corpo e da cabeça ocupou o mesmo espaço no desenho, o que possibilitou a visualização das duas imagens de uma mesma pessoa. 
pois tem seios, mas não tem curvas; em compensação, a imagem 7 apresenta uma mulher de quadril bastante largo, principalmente na versão "comportada", passando a impressão de ser mais jovem quando é mais sexualizada. Na última imagem, de número 8, também é evidente o fato de ser uma mulher, seja pela indicação de busto, como do quadril mais largo que a cintura.

Passamos agora a apresentar as imagens criadas pelos professores pesquisados.

\section{Imagem 9}

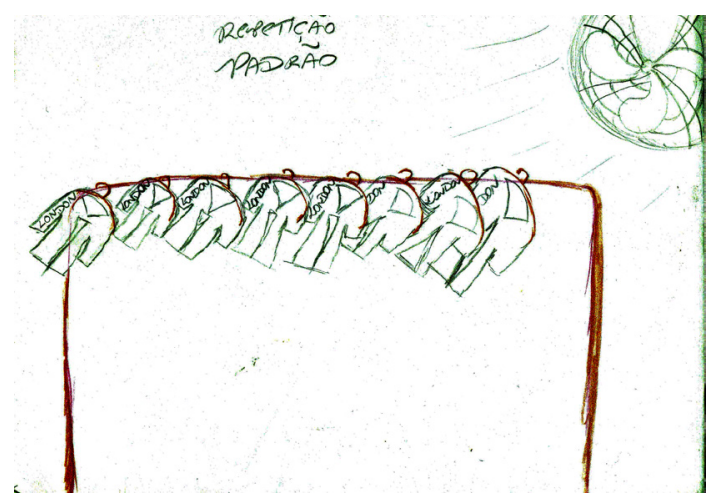

A imagem 9 mostra um figurino que é um guarda-roupa com todas as roupas iguais. Os professores que fizeram esta proposta pretendiam expressar a padronização, a repetição dos professores. Ao apresentar este figurino, o professor comentou que, mesmo que você queira fugir de um padrão, acaba caindo em outro ${ }^{\text {I5 }}$.

É interessante observar que os figurinos propostos pelos professores se relacionam muito mais com situações vividas como docentes do que com suas lembranças sobre os professores que tiveram.
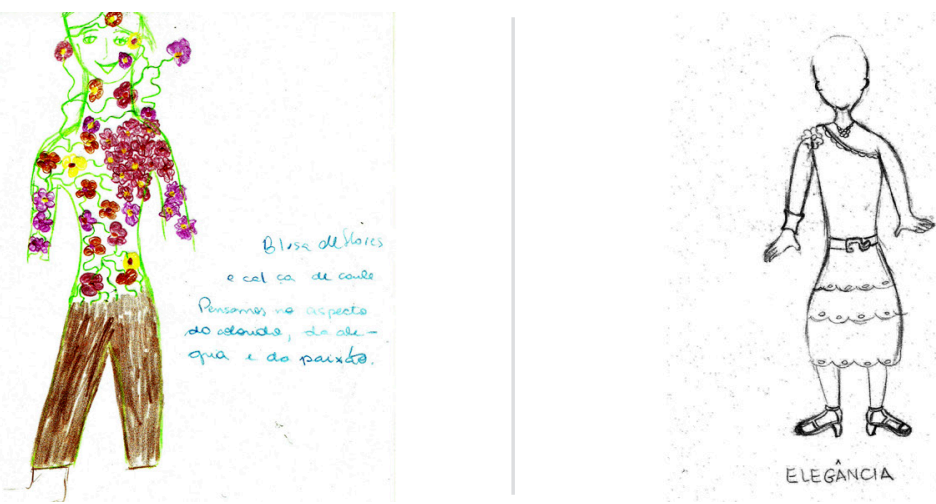

ELEGANCIA

\section{Imagens Io (esquerda) e II (direita)}

I5 Na escola onde a pesquisa se realizou todos utilizam uniformes: alunos, professores e coordenadores. Os uniformes dos professores são iguais aos dos alunos, somente uma camiseta com o logo da escola; e os coordenadores e diretores possuem um uniforme diferenciado, com saia/calça, camisa e paletó. 
A imagem Io escolheu como aspecto a ser retratado a paixão pela docência e apresentou um figurino muito florido e colorido. Esta imagem parece ser a única na qual se evidencia o corpo de uma mulher, não deformado ou infantilizado, caracterizando algo bom da docência. O figurino traz elementos da natureza, como as flores, e escolhe a cor da terra e dos troncos para as pernas. A blusa não é rígida, as flores dão a impressão de movimento e rodeiam também a cabeça desta professora. Os cabelos são desenhados com traços semelhantes aos que compõem a blusa, possibilitando um diálogo, uma unidade desta figura. Enfim, um figurino que expressa um aspecto positivo presente na docência, que é a paixão por ensinar.

A Iimagem II apresenta um figurino de uma mulher que, segundo as autoras, teve como motivação expressar a elegância, ressaltando o fato desta característica ter sido mais presente antigamente do que é hoje. Na imagem é possível ver um corpo de mulher com roupas que denotam o cuidado com sua aparência, pelo uso de acessórios, tais como colar, cinto ou pulseira e sapatos de salto. Não se mostra uma mulher que esconde seu corpo, como nos figurinos 8 e 9, mas tampouco se apresenta de maneira exageradamente sexualizada, como na imagem 9. Esta mostra o ombro, tem cintura, é elegante, mas a sexualidade não é sua característica marcante.
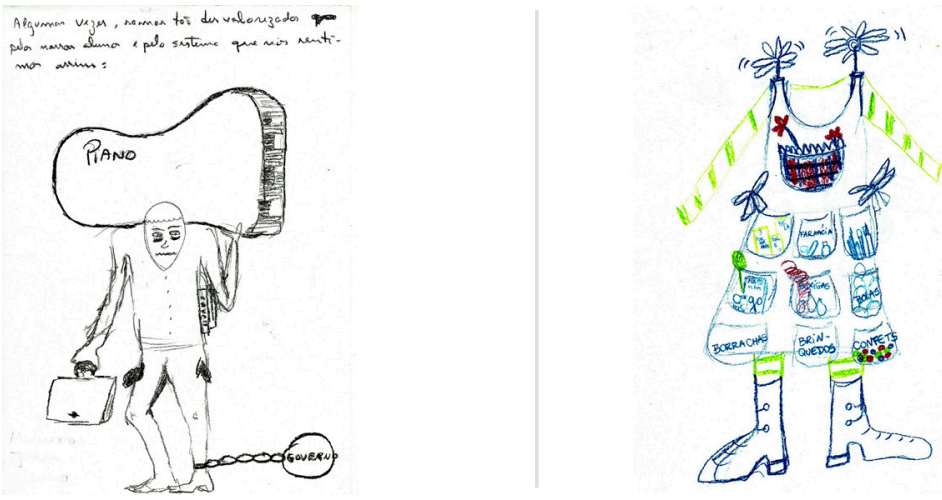

Imagens I2 (esquerda) e I3 (direita)

A imagem I2 mostra alguém carregando um piano nas costas, com uma pasta em uma das mãos e uma bola de ferro presa a um dos pés. Os professores que fizeram este figurino afirmaram que a escolha foi motivada pelo fato de se sentirem muito desvalorizados em alguns momentos, pelo total descaso dos alunos pelo trabalho proposto. É uma imagem deprimente do professor, que, além de carregar um piano e ter uma bola de ferro nos pés, tem olheiras profundas e os bolsos vazios. A sobrecarga e a tristeza desta figura são marcantes.

A imagem I3 propõe como figurino um grande avental, cheio de bolsos com muitas coisas dentro: borrachas, brinquedos, confetes, bolas, bexigas, "farmácia" etc. Ao apresentarem este figurino, uma professora (de teatro) relatou que, quando abre sua bolsa, em casa, encontra diversos objetos que ela provavelmente pega no decorrer do dia e coloca na bolsa: tampinhas de caneta, papéis etc. e discorreu sobre o peso de carregar tantas coisas e materiais. Embora o relato e o personagem tivessem um peso, era um peso muito diferente do apresentado na figura anterior, mesmo que, 
em alguns momentos, tivesse a sensação de carregar lixo na bolsa. A associação feita pela professora com o mambembe, como algo desleixado, também poderia ser vista dentro de outra perspectiva do mambembe: como atores que caminham levando arte, diversão e conhecimento por onde passam. Este figurino apresenta o professor como um clown, passando uma sensação forte de satisfação divertida ou de satisfação com o que faz.

\section{CONSIDERAÇÕES FINAIS}

O fato de precisarem refletir e escolher que imagem de professor gostariam de retratar e quais aspectos da docência gostariam de valorizar na criação do figurino, permitiu aos dois grupos entrarem em contato com aspectos significativos da docência e questioná-los.

O trabalho inicial com as memórias docentes auxiliou tanto os estudantes universitários como os professores a tomarem consciência do quanto a roupa trajada deixa marcas, constrói imagens sobre ser professor. Durante a criação dos figurinos, tiveram a oportunidade de criticar e ressignificar essas imagens. Nesse processo, refletiram sobre o movimento de identificação da criança com seus professores, percebendo que algumas características podem nos aproximar ou nos distanciar dos nossos alunos.

Os figurinos desenhados pelos professores apresentam a vivência da condição docente atual, mas a lembrança de seus professores está muito pouco retratada. Notam-se claramente aspectos enfrentados por eles no cotidiano da escola, e aparece o sofrimento causado pelos muitos aspectos da docência, das relações pessoais, das regras institucionais, do cansaço, da rigidez, do pouco reconhecimento social. Ainda que de forma menos explícita, também é mostrada a paixão por lecionar. Fica clara a diferença entre os que já são professores, em alguns casos, há muitos anos e os alunos que ainda não são, que têm como imagem docente a mistura entre os professores que tiveram e os que desejam ser.

Este texto apresenta uma possível análise de um dos aspectos de uma pesquisa que explora outros elementos da cena teatral. Parte do que foi aqui apresentado foi discutido com os participantes, porém a análise detalhada das imagens, permitida pela distância do vivido, revelou aspectos não percebidos no momento do trabalho com os grupos. Certamente, as formas de olhar para cada um dos desenhos seria muito diversificada, caso cada participante o fizesse. Este texto é apenas o diálogo da pesquisadora e sua supervisora.

Esta análise nos permite observar os muitos elementos e as múltiplas visões da docência que este exercício pode possibilitar. Além do se dar conta da importância que a roupa adquire e do quanto ela pode expressar aspectos significativos e marcantes para os alunos, a criação dos figurinos expressou, de forma simbólica, os muitos professores que os sujeitos tiveram, são ou serão. Entendemos também ter permitido a reflexão sobre qual (ou quais) cada participante gostaria de ser.

Recuperar nossas memórias é uma forma de podermos entender de qual lugar interpretamos o sentido de ser professor. Para o grupo de professores, foi evidente 
o quanto recuperar sentimentos e percepções da infância possibilitou repensar atitudes de professor. Para o grupo de alunos, essa vivência os fez pensar sobre aspectos a serem considerados no momento de tornar-se professor.

Relevante neste processo de recuperar memórias e improvisar, partindo delas, foi a possibilidade de ressignificá-las. Muitas lembranças tristes foram trazidas e, ao recuperá-las, não se apagaram as tristezas do momento vivido, mas podemos, como formadores, não assumir crenças impostas pelos professores naqueles momentos sobre as nossas capacidades. Recuperar estas memórias foi uma oportunidade de distanciar-se dessa visão sobre si, podendo deixar de lado uma sensação de incapacidade.

Evidentemente, este processo pelo qual passamos não possibilitou uma transformação completa ou uma libertação de qualquer visão pessimista de cada participante. Apenas identificamos essa possibilidade, a possibilidade de termos ressignificado situações e capacidades, ao olhar para essas lembranças e criar sobre elas.

\section{SOBRE AS AUTORAS}

ALESSANDRA ANCONA DE FARIA formadora pelo Instituto Avisa Lá, pós-doutorada na Faculdade de Educação da Unicamp com bolsa Fapesp, desenvolveu pesquisa na qual investiga a imagem do professor, partindo de sua memória e do jogo teatral. Doutora em Educação pela PUC/SP (2009), mestre em Teatro Educação pela ECA/USP (2002), graduada em Licenciatura Plena em Artes Plásticas pela Faculdade de Arte Santa Marcelina (I987). Tem experiência na área de Arte e Educação, com ênfase em Teatro, atuando principalmente na formação de professores.

E-mail: leleancona@hotmail.com

ANA ANGÉlica medeiros albano licenciada em Desenho e Plástica pela Fundação Armando Álvares Penteado/SP (I972); mestra em Psicologia da Educação pela USP (I983); Especialista em Cinesiologia pelo Instituto Sedes Sapientiae (I990) e doutora em Psicologia Social pela USP (I995). Atualmente é professora da Faculdade de Educação da Unicamp, pesquisadora do Focus Group for Creativity in Education, da Fundação Marcelino Botín, Santander/Espanha (desde 2009) e do Imagination and Education Research Group/IERG - Simon Fraser University/Canadá (desde 2003). Implantou e coordenou projetos sociais de Iniciação Artística nas Prefeituras de São Paulo, Santo André e Diadema (de I983 a I997). Suas pesquisas estão focadas na observação de histórias de iniciação na arte de artistas e de educadores.

E-mail: nanalbano@uol.com.br 


\section{REFERÊNCIAS BIBLIOGRÁFICAS}

FARIA, Alessandra. A. Contar histórias com o jogo teatral. São Paulo, Perspectiva, $20 I I$.

FISCHER, Ernst. A necessidade da arte. Rio de Janeiro, Zahar, I967.

JOSSO, Marie-Christine. Caminhar para si. Porto Alegre, EDIPUCRS, 2010.

PASSEGI, Maria C. A experiência em formação. Revista Educação - Dossiê Pesquisa (Auto)biográfica e Formação, v. 34, n. 2, 20 II.

RIOS, Terezinha. A. Compreender e ensinar: por uma docência da melhor qualidade. São Paulo, Cortez, $200 I$.

SPOLIN, Viola. Jogos teatrais para a sala de aula: um manual para o professor. São Paulo, Perspectiva, 2008.

ROUBINE. Jean. J. A linguagem da encenação teatral. Rio de Janeiro, Jorge Zahar, I998.

VIANA, Fausto. R. P. O figurino teatral e as renovações do século XX. São Paulo, Estação das Letras, 20I0. v. I, 296p.

VIANA, Fausto. R. P.; MUNIZ, Rosane (org.). Diário das escolas: cenografia. Rio de Janeiro, Funarte, 20II. v. I, 240p. 